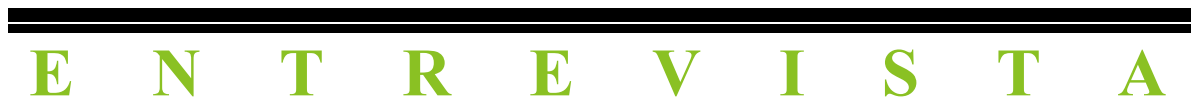




\section{ENTREVISTA A GUSTAVO BUENO}

Manuel Atienza.-¿Cuál sería, a grandes rasgos, su biografía intelectual, poniendo énfasis en los puntos de contacto con el Derecho?

Gustavo Bueno.-El primer punto de contacto es que estudié Derecho, aunque no terminé la carrera. En Zaragoza, año 1941 ó 1942, me matriculé en la Facultad de Derecho, juntamente con la Facultad de Filosofía y asistiendo a clases de Medicina, porque estaba dudando en la alternativa a seguir. El Derecho me interesó muchísimo, por lo menos en los primeros cursos. Me parece que llegué hasta tercero o algo así. El Administrativo me espantó.

M.A.-¿Y el Derecho natural?

G.B.-El Derecho natural me gustaba mucho. También estudié Derecho Civil; confieso que me interesaba muy poco. En cambio, me interesó mucho después, a posteriori, al cabo de los años. Recuerdo que me compré los famosos tomos de Castán a los cinco o seis años, para leerlos por puro interés, por pura curiosidad, por meterme un poco en el juego. Luego, me despegué enteramente de los intereses por el Derecho en general, aunque siempre mantuve un interés grande, que ha sido muy intermitente, claro. En los años 50, tuve bastante contacto a través de Antón Oneca, que era catedrático de Derecho Penal en Salamanca. Con él conviví tres o cuatro años en un Colegio Mayor. Todavía tengo yo en casa obras suyas sobre Dorado Montero-, tenía trabajos sobre el asunto y artículos que me dejaba; era un hombre mayor que yo, hijo del famoso Antón, el antropólogo, y tenía una perspectiva muy curiosa, se ve que estaba influido por su padre, por la antropología y demás. El otro punto de contacto, que recuerde, fue en Oviedo con el profesor Atienza y Elías Díaz. Se trataba de una Facultad de Derecho muy en auge. Por los años setenta pudo ser aquello...

M.A.-Comienzos... sí, de los setenta.

G.B.-Y teníamos mucho contacto: precisamente, yo estuve en la tesis doctoral del profesor Atienza sobre La Filosofía del Derecho en Argentina...

M.A.-Así es. 
G. B.-... interesantísima por la abundancia de información y de análisis. Recuerdo además que las facultades de Derecho eran mucho más formalistas que las nuestras en general, pero en Oviedo sobre todo. Recuerdo que casi sin enterarme, cuando estábamos preparando la entrada al Tribunal, me encajetaron allí una toga y tuve que ir con toga al Tribunal; la primera vez que me la ponía en toda mi carrera, pues he pretendido evitarlo en lo posible. Precisamente, otra vez que también coincidimos en Oviedo fue el año pasado, pero entonces ya estaba acostumbrado ¿verdad? Ya me puse la toga porque me la había tenido que poner varias veces. Yo soy el primero en reconocer que merece la pena hacer una ceremonia de verdad, para hacerlas bien.

M.A.-¿Cómo trazaría usted su evolución intelectual, tratando de resumir en la medida en que se pueda?

G.B.-Ayer hablábamos de la palabra evolución. En un sentido amplio, depende de la escala en que te pongas, porque muchas veces también se tiene la impresión -sobre todo cuando se está a muchos años de distancia de lo que fueron tus comienzos- de que no te has movido nunca de la misma situación. Recuerdo perfectamente cuáles fueron las primeras páginas que yo escribí y que no sabía que eran filosofía. El primer problema que se puede llamar filosófico era a cuenta de un profesor de ciencias naturales que yo tenía en Zaragoza, que nos decía, haciendo clasificaciones de plantas y animales, de un modo muy solemne y muy terminante: «la excepción confirma la regla». La fórmula me producía una impresión, una fascinación, pues yo no entendía aquello. Recuerdo que debía estudiar sexto curso o séptimo de bachillerato y escribí unas hojas en un cuaderno sobre esto. Pregunté en qué Facultad, en qué sitio, había que estudiar esto, y me dijeron que esto era filosofía. Y por eso me dediqué a la filosofía.

M.A.-Lo mismo le podrían haber dicho: «esto es Derecho».

G.B.-Lo mismo, es exactamente lo mismo, pero como el canal había sido las ciencias naturales, las taxonomías... Pero lo mismo es. Exactamente lo mismo. «La excepción confirma la regla» plantea todos los problemas de las leyes científicas, de las normativas jurídicas. No es una cuestión puramente de adolescente, es absolutamente fundamental; quiero decir que no fueron problemas de índole metafísica, era más bien un problema de tipo lógico. De manera que mi orientación inicial fue por las ciencias naturales. Yo tenía un interés muy grande por la biología. En aquél tiempo no había biología: había medicina, había que ser médico, y a mí ser medico no me interesaba, tenía la experiencia de mi familia, que eran médicos pero no eran científicos, y a mí me interesaba la medicina en su parte biológica. Este interés contribuyó a que estuviera muy en contacto con el tema: yo iba a las clases de anatomía en Zaragoza y luego volví en Salamanca. Después me interesé mucho 
por la lógica y por las matemáticas. Durante los primeros años explicaba lógica; luego, tuve que explicar antropología por razones extrínsecas: cuando se creó la Facultad de Filosofía en Oviedo no había catedráticos, ni había disciplina, ni gente y me encargué yo de esta asignatura. He estado casi quince años con ella. Por otra parte, me interesó muchísimo, claro, la escogí a propósito. últimamente me intereso mucho por cuestiones jurídicas.

M.A.-Y por cuestiones políticas.

G.B.-Sí, por cuestiones de filosofía política y por cuestiones de filosofía de la religión, por supuesto.

M.A.-Esto desde el punto de vista temático. ¿Y desde el punto de vista de la orientación filosófica?

G.B.-¿De la orientación? Pues bien, por las razones que me ha tocado a mí desarrollar, ha sido una orientación muy ecléctica. En principio, tuve una influencia muy grande de toda la escolástica en Salamanca. Hay que decir que yo estaba en posiciones personales que podríamos llamar de un racionalismo ilustrado tipo volteriano. Para algunos jóvenes estudiantes, la formación era Voltaire, era Anatole France; esa ideología, en la época de los años cuarenta y cincuenta, era completamente imposible manifestarla. Eramos un grupito de amigos que, más o menos, manteníamos esa cantinela ¿no? Pero, independientemente de esto, la afirmación de que a mí me interesó mucho la escolástica, en los años cincuenta en Salamanca, no tiene ninguna relevancia en aquella época donde era la doctrina oficial. Por eso puede resultar curioso o paradójico desde la posición en la que yo estaba. Descubrí aquella cantidad de infolios que yo no había visto nunca juntos, por una bibliotecaria que era amiga de prestárnoslos. Ahora ya aquello está como un museo: ya no dejan sacar los libros, están encerrados. Pero en aquellos años los libros te los podías llevar a casa. Al mismo tiempo, encontré en Salamanca una bibliografía espléndida de lógica: Círculo de Viena, Bertrand Russell, etc.

M.A.-¿Podría decirse que en algún momento, vinculado con algún tipo de suceso, usted empezó a tener una concepción materialista de la filosofía?

G.B.-Ya, muy bien. En Salamanca conocí a Tierno Galván, tuve mucha relación con él. Mi orientación era más bien...

M.A.-¿Hablamos de los años cincuenta?

G.B.-Sí, años cincuenta. Mi orientación era siempre de índole materialista; lo que pasa es que era un materialismo sin definir: era Aristóteles tomado siempre desde esa perspectiva. Era Spinoza. El tratado de Spinoza lo leía yo metido en las tapas de un devocionario cuando había que ir a misa, para poderlo leer, porque aquello era imposible, de manera que para mí Spinoza era una especie de libro... casi de... un devocionario, realmente hacía 
las funciones de un libro de misa. El marxismo, concretamente, yo lo descubrí también a través de los escolásticos.

M.A.-¿A saber?

G.B.-Por ejemplo, un libro del Padre Llovera que debo tener en casa, podía ser de los años 1912 ó 1920. Se llamaba Sociología Cristiana. Lo que no me acuerdo es si estaba en latín o en español. Era un tratado escolástico que debía de ser una novedad, porque la sociología era una disciplina un poco exógena para la fílosofía escolástica, pero aplicaba allí aquel señor los temas de la cuestión social, que se llamaba en el siglo pasado. De manera que era un índice muy atractivo porque hablaba de cuestiones políticas, sociales, económicas, de la cuestión obrera y demás. En alguno de aquellos capítulos, hablaba del marxismo. Eran quince o veinte páginas. Yo lo volví a releer al cabo de los años para compararlo con Martha Hannecker; con todos los respetos para Martha Hannecker, creo que era superior lo del Padre Llovera, porque era una exposición que más o menos te informaba de la plusvalía, del mecanismo de la lucha de clases; luego los refutaba, pero en fin, eso era lo de menos. Una ventaja que le he encontrado siempre a la escolástica es que, por su carácter de recoger la tradición platónica -porque al fin la escolástica es de tradición platónica-, se veían obligados los escolásticos a reconocer al adversario y, entonces, a través del adversario te enterabas de muchas cosas que si no, no podías enterarte.

M.A.-Sobre esto, a mí me ha parecido, sobre todo en estas últimas conferencias -siempre lo había sospechado-, que usted tiene una gran formación retórica, en el sentido digamos clásico de La Retórica de Aristóteles.

G.B.-Puede ser. Puede ser también la costumbre. Por supuesto, me interesa mucho la retórica desde el punto de vista teórico, pero no la he practicado, quiero decir que no he dado clases de retórica. Ha sido más bien seguramente la costumbre y sobre todo la afición: a mí me gusta mucho más hablar que escribir, para mí escribir es un tormento completamente.

M.A.-La retórica en la antigüedad y, ahora, la nueva retórica han surgido un poco en contextos jurídicos.

G.B.-Sí, por supuesto, eso siempre lo vi con mucha claridad, con mucha evidencia. Por cierto, para agregar a esta pregunta que me hacía al principio de mis contactos con el Derecho, yo recuerdo que he tenido, en Salamanca también, un amigo fiscal y un amigo juez que me invitaban a ir a un juzgado de Primera Instancia a presenciar los juicios. Me divertía mucho viendo aquello. Eran juicios de menor cuantía pero veía cómo funcionaba. Y también he tenido contacto con el mundo jurídico como acusado: he estado en un juicio que ha durado casi seis años, que fue desde el juzgado de Primera Instancia hasta la Audiencia de Oviedo y hasta el Tribunal Supremo, de manera que he tenido como acusado todos los caminos del cursus. 
M.A.-Desde un punto de vista externo e interno. Pasando a otra cosa, ¿qué le parece una frase que a mí siempre me impactó de Toulmin: él dice, en uno de sus libros, que la lógica es «jurisprudencia generalizada» o, mejor dicho, que debería considerarse «jurisprudencia generalizada»?

G.B.-Lo encuentro bastante acertado, bastante aproximado. La lógica surge en la sofística griega. Los sofistas eran lo que hoy diríamos abogados. Realmente los sofistas, algunos sofistas, los sicofantes, etc., eran individuos que adquirían el arte de la retórica y de la dialéctica precisamente para defender en el juicio y hacer lo blanco negro, convertir lo blanco en negro; entonces allí se estrenó realmente. Todo el estudio de Aristóteles de la silogística está basado en una especie de confrontación entre los razonamientos diríamos procesales o jurídicos. La sofística, como sabemos, es una denominación ya peyorativa que viene de la tradición platónica pero que, naturalmente, no hay que tomar siempre así. Cuando empleamos la palabra sofista siempre inyectamos una especie de contenido peyorativo que no se debe. Los sofistas son simplemente hombres de mundo, inteligentes y llenos de ingeniosidades; por ejemplo, los famosos argumentos de Protágoras cuando aquel famoso dilema, que está en los principios de los rudimentos de la lógica y de la dialéctica.

M.A.-De hecho, el origen de la retórica es jurídico.

G.B.-Claro, es jurídico por eso, totalmente. Es más, yo tengo una teoría de la lista de categorías de Aristóteles, la famosa lista de ocho o diez categorías, que parece ser una lista puramente metafísica u ontológica: sustancia, cantidad, cualidad, relación... entonces la pregunta es: ¿de dónde ha sacado Aristóteles esta lista? Y cómo en el momento de tratar de establecer una enumeración de las categorías del ser ¿por qué dice diez y no dice quince o veinte? ¿Por qué dice éstas y no otras? A mí me dio la pista precisamente, entre los escolásticos, al analizar la categoría del hábito, el egeim, que en los manuales, se entendía un poco como los psicólogos hoy en día, como cualidad. Porque seguramente a los autores de muchos manuales les parecía una especie de descuido que al lado de cosas tan solemnes como pudiera ser la sustancia o la cantidad, se pusiera un sombrero, por ejemplo. Pero resulta que el «hábito» de Aristóteles es el indumento, es el traje, es el hábito, seguramente la única categoría de contenido antropológico que se encuentra en Aristóteles. Esto me dio la pista (unido a que la palabra «categorein» significa acusar, y acusar en juicio) de que pudiera ocurrir que la lista de categorías está tomada por Aristóteles del sistema de ejes según las cuales se pregunta a un acusado: ¿quién eres tú? «sustancia», ¿cuándo ocurrió el suceso, el delito? «tiempo», ¿cómo estabas?, ¿dónde estabas...? Es decir, todas las categorías tienen una aplicación jurídica. Esto se refuerza después con el otro foco de fundación filosófica, me refiero a Kant. Kant está 
todo lleno de referencias jurídicas en la Crítica de la Razón Pura: el tribunal de la razón, deducción trascendental. Yo estoy completamente convencido de que lo que se llaman «argumentos de abogado» proceden de estos antecedentes; incluso reglas que se utilizan en teología y que además son bastante discutibles, por ejemplo: onus probandi, a quién pertenece probar un argumento, o también, esto que se dice varias veces sobre la existencia de Dios, que generalmente es opinión común: la existencia de Dios tiene que probarla quien la afirma, no quien la niega; esto es un argumento de abogado.

M.A.-Es un argumento procesal.

G.B.-...claro, es un argumento procesal, que filosóficamente tiene muy poco valor, en este caso concreto, es simplemente una excusa: «yo no quiero saber nada, yo no creo en Dios, el que afirme a Dios que lo pruebe». Pero se puede plantear del otro modo. Sin embargo, esto indica la importancia del marco jurídico, porque a fin de cuentas es la situación en donde dos personas sobre cosas relativamente concretas, con unas reglas del juicio, están discutiendo. Creo que es elfundamento realmente de la dialéctica. Yo muchas veces he defendido -e incluso he orientadoa alguien que me ha solicitado dirigir una tesis doctoral sobre casos de moral y demás, que lo mejor que podía hacer es estudiar Derecho. En lugar de empezar a inventarse situaciones más o menos fantásticas, como si A promete a B y ver qué pasa ahí, vaya al Derecho Romano o a la jurisprudencia del Tribunal Supremo y encontrará situaciones reales mucho más ricas que las que se pueda usted inventar en abstracto para tratar un caso de moral completamente inventado; como era muy frecuente entre la moral, tal y como se estudiaba en tiempos en las Facultades de Filosofía, que eran unos casos absolutamente gratuitos inventados por el profesor en aquel momento, que no tenían pies ni cabeza.

M.A.-Ayer usted habló en un momento de la distinción entre contexto de descubrimiento y contexto de justificación, y lo hizo básicamente desde la perspectiva crítica. Esa distinción, en Filosofía delDerecho, se ha usado muchas veces -yo concretamente la he usado, pues me pareció que era clarificadora- para explicar la argumentación jurídica y, en concreto, explicar qué quiere decir que los jueces deben motivar las decisiones: que eso debe entenderse en el contexto de justificación y no en el de descubrimiento. ¿Le parece que la distinción, en ciertos contextos como éste, sí que se puede o que se debe usar?

G.B.-Sin duda, yo creo que sí. Además, yo no negué la distinción, más bien intenté reinterpretarla desde un punto de vista dialéctico, precisamente, más o menos, en la línea que usted apunta ahora. Es decir, la distinción de Reichenbach tal como se elaboró en el Círculo de Viena; y el uso que se 
ha hecho después de ella, que consistía prácticamente en eliminar la génesis, las cuestiones de génesis como impertinentes para un planteamiento de un argumento de estructura, $y$, a veces, de un modo absolutamente provocativo: «es que yo no sé nada de historia, ni lo quiero saber, porque no tiene nada que ver con el asunto». La distinción se convertía inmediatamente en esa dicotomía de historia-descubrimiento-génesis y estructura. Efectivamente, tiene su razón de ser. Recuerdo ahora el libro famoso de Hadamard, Psicología de la invención en el conocimiento matemático, donde va estudiando una serie de situaciones muy abundantes: recuerdo el caso de Kekulé, cuando descubre los anillos de los bencenos; el de Poincaré, cuando descubre las funciones fuchsianas, que es sorprendente, habiendo trabajado un poco sobre las funciones fuchsianas, una cosa tan absolutamente intemporal, impersonal, que parece que se sostiene a sí misma. Cuando se lee lo que hizo Poincaré antes de descubrirla, las cosas que le ocurrieron y cómo lo descubrió de golpe, dando vueltas a otro asunto: se le ocurre una cosa, baja de un autobús en París, baja distraído, entonces da un tropiezo yen aquel momento descubre la solución ¿qué tiene que ver todo lo que hizo Poincaté, el proceso de descubrimiento, con la estructura de las funciones fuchsianas? No tiene nada que ver. Parece que ahí hay conexiones que nos dicen que la distinción es total, evidente, pero hay otras en donde esto no ocurre, esa es la cuestión. En general, yo creo que hay veces que hay estructuras que incluyen a la génesis y hay estructuras que no la incluyen, eso es sencillamente; por ejemplo, y para referirme al problema de la evolución, a mí me parece evidente, hasta cierto punto también, que las cuestiones de estructura, por ejemplo orgánica, biológica, en tanto que constituyen un sistema termodinámico, por ejemplo, morfológico, que está funcionando, pueden disociarse casi totalmente de las cuestiones de génesis, es decir, de dónde procede ese organismo. Pero, por otra parte, si se quiere explicar de un modo cada vez más profundo porqué funciona ese organismo, es imprescindible ir a las cuestiones de génesis, es decir, al código genético, concretamente, y la propia embriología es la única disciplina que ha permitido entender ciertas condiciones anatómicas que por sí mismas son ininteligibles. Ahí la génesis está incluida realmente en la estructura. Otras veces no, por ejemplo: en situaciones físicas. La génesis puede ser eliminada muchas veces pero en situaciones orgánicas no, y en situaciones antropológicas tampoco; aunque aquí está la cuestión de la historia. Cuando uno está en una ceremonia, una experiencia que me ha ocurrido muchas veces, en la apertura de cursos de la Universidad, donde es una ceremonia solemnísima y, como aquello dura muchísimo, para hablar de algo con el que tienes al lado le preguntas: ¿y por qué haremos esto? ¿por qué llevaremos estos colores, unos amarillo, otros rojo...? ¿y estas borlas, que tienen aspecto eclesiástico? 
Empiezan a ser cuestiones de génesis, pero si hay algún claustral realmente identificado con eso, me dirá, como me dijo alguien una vez, «déjate de historias», «qué más da de dónde vengan, la cosa es ésta». Ahí la génesis parece que comprometía un poquitín la estructura, que es muy curioso, y es lo que pasa también en política.

M.A.-Y en realidad en Derecho, porque el punto de vista de este segundo señor es lo que nosotros consideramos el punto de vista interno, y el juez necesariamente, hasta cierto punto, tiene que asumir un punto de vista interno.

G.B.-Claro, por supuesto, es evidente. La decisión es sumamente compleja, tiene muchas líneas y yo creo que hay que decir que hay estructuras que implican la génesis y el descubrimiento y otras que no, por lo tanto que no se puede generalizar.

M.A.-Volvamos un momento a cuestiones de biografía intelectual. En el año sesenta me parece que es cuando usted llega a Oviedo como catedrático. ¿Su concepción de la filosofía era entonces ya una concepción materialista?

G.B.-La llegada a Oviedo yo la deseaba. La elegí: quiero decir que podría haber ido a otras partes, pero elegí Oviedo precisamente por sus circunstancias. Había oído que era entre las universidades de aquellos años (todavía faltaban quince o veinte años para el final del franquismo) la que más expectativas ofrecía, por lo que a mí me habían contado: porque estaba relativamente apartada de los centros del poder y control, porque había unos cinturones de mineros al lado de la industria. Me gustaba mucho. Yo había leído muchas cosas del marxismo y del materialismo histórico. Y, entonces, aquello fue como ver en funcionamiento la diferencia entre el «cinturón de incienso» de Salamanca, que era una ciudad llena de conventos y de frailes (la Universidad Pontificia era la que tenía el peso fundamental) y el cinturón industrial de Oviedo. En Oviedo, la gente no sabía muy bien que existía la universidad. Recuerdo que al primero que pregunté por dónde estaba la universidad, cuando iba a tomar posesión, no sabía lo que era aquello, creía que era un colegio. No pasa hoy así, pero en aquella época sí. Eso en Salamanca hubiera sido totalmente impensable: la Universidad era el punto de referencia. En Oviedo, la Universidad era una parte más entre otras. Y eso a mí me gustaba mucho, porque te permitía salir un poco de la «torre de marfil» que es la Universidad. De ese peligro que hay de encerrase en la Academia como si fuera el centro de la sabiduría y del mundo. Entonces, puedo decir, respondiendo a la pregunta, que en Asturias cristalizó, inmediatamente, una serie de expectativas que yo podía tener; cristalizó una serie de alternativas más o menos teóricas ante el contacto con una serie de problemas que en Salamanca no se veían. 
M.A.-Dejándole a usted aparte, ¿cuáles diría que han sido los grandes filósofos en España, después de la Guerra Civil? Empezando, supongo, por Ortega.

G.B.-Sí, ya, por supuesto Ortega.

M.A.-¿Usted conoció a Ortega?

G.B.-Sí, le he visto dos veces. Es muy curioso además el caso de Ortega... Conocí a Julián Marías también en Madrid. Pero con Julián Marías no tuve trato porque no me gustó su carácter, no había «química» como se dice ahora. No me gustó, lo cual no quiere decir ninguna crítica, simplemente que por carácter no encajaba yo con la psicología de aquel señor.

Había entonces una actitud muy beata hacia Ortega. Mi situación, en aquel entonces, era de un radicalismo sin límites; precisamente, porque no se podía hacer nada. Era un radicalismo verbal, intelectual, pero luego nada.

M.A.- ¿Usted a Ortega, lo conoció en alguna conferencia?

G.B.-A Ortega le conocí en la conferencia del Ateneo sobre el teatro, cuando volvió a España. Y, precisamente, estuve en el Ateneo junto con Gonzalo Fernández de la Mora, que era muy orteguiano. Luego, fue Ministro de Obras Públicas, me parece, en los años setenta...

M.A.-De una manera muy sintética, ¿cuál ha sido la mayor importancia de Ortega?

G.B.-Sí, a Ortega yo lo descubrí muy tarde. Por una razón: por la influencia del ambiente, como es natural. Entonces, la Facultad de Madrid era una Facultad donde estaba el padre Ramírez, el padre Barbado, el padre Sancho, el padre Zaragüeta; es decir, era como un seminario. Algunos eran muy buenos; por ejemplo, el padre Barbado era un dominico que había estudiado con Cajal, era biólogo y era de primera. Es pura frivolidad decir que era una facultad de curas.

Acaba de publicarse un libro sobre Ortega de Gregorio Mora que, por cierto, tengo que presentar en Oviedo en cuanto vuelva de Alicante. Es un libro importantísimo sobre Ortega, porque ha estado ocho o diez años trabajando sobre él. Gregorio Mora se dedica al periodismo en Barcelona, aunque es de origen asturiano. Se ha dedicado a hacer una reconstrucción de la biografía de Ortega, realmente increíble; y allí, el libro, que es muy bueno, sin embargo adolece de tener una visión de Ortega exclusivamente política. Él se va preguntando qué hace Ortega en aquel momento en París y por qué, en Alemania en tal sitio y por qué; y, entonces, va siempre sacándole conexiones con el franquismo. Ortega resulta una especie de prefascista o fascista entero.

Yo creo que Ortega es una figura absolutamente de primer orden, de primera magnitud; su importancia ha sido extraordinaria. En España constituye un cambio de giro en el modo de hacer filosofía; por la actitud que tenía él frente a las ciencias naturales, frente a la historia-, es decir, que hacía filosofía 
a pesar de que no tuvo tiempo u ocasión y estaba consciente, perfectamente, de que tenía que escribir en los periódicos para ser leído. Muchas veces no pudo profundizar en muchas cosas-, por ejemplo: no profundizó para nada en el darwinismo. Le tocó la ola antidarwinista; cuando se estaba haciendo la nueva síntesis famosa, a consecuencia de la interpretación del mendelismo. Le tocó ser antidarwinista. Y le tocó ser antimarxista: tampoco conoció bien a Marx. De manera que cuando el centenario de Ortega en 1983, y el centenario de Marx, y el de Darwin, saltaba a la vista que Ortega había quedado completamente marginado de las grandes corrientes, al margen de lo que supiera de ellas, como podía ser el darwinismo y el marxismo. A pesar de esto, la obra de Ortega es fundamental. Sobre todo la actitud de Ortega ante la filosofía española. Creo que es un punto de referencia. Yo con Ortega, biográficamente, estaba muy influido por el ambiente general en donde a Ortega se le llamaba «culturalista». Todavía tengo un libro, precisamente de un canónigo de Alcoy, que se titulaba así: ¿Es Don José Ortega y Gasset un filósofo propiamente dicho? En un montón de páginas, demostraba que no, que era un culturalista, un ensayista, etc.

Con Ortega tuve la mala suerte de leer un día, siendo estudiante en Zaragoza, la Musicalia; unas notas de Ortega, que estaban publicadas en un tomito aparte en Espasa Calpe. Y, claro, Ortega no sabía nada de música, le pasaba lo que a Hegel, que lo más que le gustaba era Rossini. Ortega no distinguía una fusa de... y, entonces, se ve un ensayo sobre la música encareciendo a Debussy, sin saber nada de música $\mathrm{y}$, simplemente, guiándose por criterios externos: de si la música de Beethoven es para las señoritas de coutures y la de Debussy... Entonces, a mí me produjo muy mala impresión. Pero, en cambio, tiempo después, vino un agente de libros y me hizo una oferta de las obras completas de Ortega. Se las compré. Leí y estudié sistemáticamente las obras de Ortega y lo descubrí por mi cuenta.

No se puede comparar con Zubiri, por ejemplo. Yo tengo muy mala impresión de Zubiri, malísima, todo lo que se pueda pensar es poco. No digamos la que tengo de María Zambrano, que tanto se ha encarecido. Cuando hubo el centenario de Zambrano, yo no perdoné nunca que me mandaran las obras completas para que hiciera una colaboración. Tuve que pasar un fin de semana leyendo a María Zambrano. Eso es un tipo de especulación... pero claro, como aquí da igual ocho que ochenta. La filosofía de Zubiri no es filosofía, es otra cosa distinta: es una metafísica ideológica. Pero Ortega no, Ortega hizo realmente cosas distintas. Ortega es la gran tradición. Creo que le perjudicaron sus discípulos, la orientación de sus discípulos; aquí se confirma muy bien, aquello que yo recordaba el otro día, que no hay mejor discípulo que el que supera al maestro. No hay manera de que le superen: Julián Marías... y no digamos todos los demás. 
Entonces, yo, sinceramente, aunque no he conocido a Ortega más que externamente, me considero, en lo que yo pueda significar, un discípulo de Ortega; es decir, dentro de esa tradición. En cambio, renegaría completamente de Zubiri y de cualquier otro, a pesar de sus famosos conocimientos científicos, que no dudo que los tengan. Yo no dudo que Zubiri tuviera gran conocimiento de física, que tradujo libros importantes: el de Bohr, etc., lo que digo es que esos conocimientos científicos que se le atribuyen, no se ven en ninguna parte en sus obras; como si hubiera dos mundos. Si tenía formación científica, es como si le gustaran los sellos, una cosa totalmente privada; no ponía aquello absolutamente en juego en sus especulaciones filosóficas.

M.A.-Hace algunos años, leí un trabajo suyo sobre la filosofía en España donde emitía un juicio negativo: que, desde el punto de vista técnico, los filósofos españoles en activo, las generaciones más jóvenes, habían alcanzado un nivel muy alto, comparable al de cualquier país europeo, pero que, sin embargo, no había propiamente una filosofía. ¿Qué opinión tiene de la filosofía española hoy?

G.B.-Por lo que he ido viendo, yo confirmaría ese diagnóstico por una razón interesantísima de tipo sociológico. Y es que, en España, generalmente se ha tendido a concebir el oficio de profesor de filosofía como traductor o expositor crítico del estado de la filosofía en Europa y América, sobre todo en Europa. Se han escogido unos cuantos pensadores: que si LeviStrauss, en tiempos Sartre, después Foucault, Habermas, etc., y Wittgenstein, no digamos. Casi se han dedicado al monocultivo de estas exposiciones, cosa que está muy bien. Pero esto significaba no tomar contacto con la realidad de las cosas mismas, que decía Husserl. Dicho de otra manera, si hay una filosofía lingüística, a mí me parece que un profesor de filosofía lingüística lo primero que tiene que hacer es interesarse y conocer lo más posible sobre lo que hacen los lingüistas, que es la lingüística en ejercicio. Lo que no se puede hacer es filosofía lingüística sobre las teorías que han hecho Ayer o Searle. Eso es absurdo, no digo no conocerlas, pero siempre teniendo referencias. Es como alguien que quiera hacer filosofía natural o filosofía biológica y se dedica a leer libros de filosofía biológica; tiene que leer a Darwin, ir a un laboratorio. Permítame que insista en esto porque es un punto central. No se trata entonces de contraponer una filosofía hecha desde dentro, desde España, frente a la filosofía desde fuera, y decir: «bueno, me irrita que esté todo el mundo hablando de Wingenstein, explicándolo en tesis doctorales, y no se habla de lo que se hace en España», no es eso, porque entonces sería puramente un planteamiento sociológico. La diferencia es ésta: «me irrito ante alguien que está hablando de filosofía biológica y está leyendo libros de filosofía de la biología y no estudia biología». 
También me pasa con las matemáticas, etc. Ésta es la cuestión, y ésta es la principal objeción que yo haría a mis colegas en general.

M.A.-¿Cómo ve usted las relaciones entre la filosofía y la filosofía del Derecho? ¿Se podría decir que, distinguiendo entre la parte constructiva y destructiva de la filosofía, prima más en el plano de la filosofía general la parte destructiva, mientras que en el filósofo del Derecho la constructiva? ¿Y no hay un cierto problema con ser filósofo del Derecho si es que el objeto de la filosofía son ideas, que no pueden ser particulares, privativas de un territorio...?

G.B.-Yo creo que la filosofía del Derecho es una de las partes centrales de la filosofía, y lo demuestra la tradición; es decir, el porcentaje mayor del peso relativo de los intereses filosófico-jurídicos en los clásicos, desde Platón, Aristóteles, Kant, Hegel, está demostrado... no digamos Suárez, Domingo de Soto... Es decir, que las grandes figuras consideradas como filósofos han dedicado parte fundamentalísima de su obra al estudio de la filosofía del Derecho. Quizás aquí, adolecemos de una cuestión gremial de división del trabajo en las facultades de filosofía. La separación que se observa tiene que ver con que sea una facultad distinta donde se enseña la filosofía del Derecho. Ocurre lo mismo en la filosofía, entre las diferentes disciplinas o áreas de conocimiento. Resulta que se han especializado por mimetismo con las ciencias naturales; y el que se dedica a la filosofía lingüística considera intruso que alguien hable del lenguaje si no pertenece a su área. Ésta es una deformación o distorsión de lo que es la realidad. A mí me parece que la filosofía del Derecho es fundamental en un sistema filosófico. Es imposible citar un solo ejemplo de sistema filosófico importante donde no haya ocupado un punto central. Efectivamente, es una parte, pero es una pars lotalis. A propósito de la filosofía del Derecho, se tiene que hablar de las normas; y, entonces: «la excepción confirma la regla», las normas y las leyes... inmediatamente obligan al cruce con las leyes naturales que, además, son metáforas de las leyes jurídicas. La comparación de las leyes civiles, o antropológicas, con las leyes naturales es una comparación obligada. Resulta que el estudio de las leyes o análisis de las leyes, o de las normas, es tan importante que es general, aunque ocupe una parte; no se va a decir, salvo que se trate de un teólogo, que las leyes están dadas por Dios a la naturaleza y al hombre y es todo lo mismo. En ese caso no habría problema. Pero, prescindiendo de estos fundamentos, aún reconociendo que lo que llamamos normas jurídicas se extienden únicamente a una esfera antropológica, la importancia que esto tiene en relación con todo lo demás hace que sean ideas absolutamente generales, no por extensión sino por confrontación, por connotación. Lamento no haberle dedicado más tiempo, lo lamento como una mutilación, no solamente por su importancia práctica que ya sería suficiente, sino porque forma parte 
del sistema filosófico, es imposible hacer nada sin esto. Mis limitaciones en este punto las veo como una limitación y no me glorío de ellas. Lo que puedo decir es que tengo como hobby, aparte de leer artículos de Doxa, me gusta de vez en cuando leer tratados de Derecho Romano, para ver cómo funciona la «Lex Aquilia» y cosas de ese tipo, o el Código Civil o el Código Penal... me gusta ver cómo funciona, cómo razonan, esto para recalcar que mi posición no es puramente retórica, es efectiva.

M.A.-Ud. ha escrito un largo artículo sobre los derechos humanos. ¿Nos podría resumir cuál es su tesis sobre el asunto?

G.B.-En esencia, el problema que me interesó era el contexto, el sintagma por así decirlo, donde estaba incluido el rótulo de los derechos humanos, a partir de la Asamblea francesa de 1789, que era el de «Derechos del hombre y del ciudadano». Ese «y» me llamaba mucho la atención: ¿es redundante? Partí de la diferencia de la estructura lógica de los dos conceptos: la estructura lógica de «ciudadano» era la estructura de una clase atributiva, la idea de que una clase dividida por una relación de equivalencia da un cociente de clases distintas: el ciudadano de París era distinto del ciudadano de Berlín. «Ciudadano» había que traducirlo a miembro de un Estado, la «polis», la «civitas», etc. Los derechos del ciudadano son, entonces, los derechos de los franceses en cuanto franceses, en cuanto súbditos del rey de Francia. Mientras que el concepto de «los hombres» borra esas fronteras y aparece como una clase distinta. Una imagen que podía servir para ilustrar esto es la de un plano lleno de puntos frente a un plano reglado, de rectas paralelas, que forman haces de rectas donde cada recta es paralela con otra; pero, sin embargo, no dos rectas paralelas son rectas paralelas entre sí, porque pertenecen a haces distintos. Los haces diferentes forman unas clases de equivalencia que son disyuntas, es decir, no hay ningún haz que tenga una recta en común con otra porque entonces sería el mismo haz. En cambio, los puntos son uniformes. En conclusión, los hombres serán los puntos y los ciudadanos serán los haces. Inmediatamente, aparecía la idea del conflicto entre los hombres, vistos etológicamente así, los derechos de los hombres y los derechos de los pueblos. Esto luego se tradujo en la legislación ulterior, en el año 1948, con la Declaración de Derechos Humanos de la ONU. Más tarde, vino la Conferencia de Argel donde, en cierto modo, se estaban atenuando, limitando... porque los derechos de los pueblos dejan en suspenso o determinan muchos derechos humanos. Ésa era la idea.

M.A.-Esa distinción sigue funcionando hoy. En la Constitución, por ejemplo, se supone que algunos son derechos de cualquiera y otros son, por ejemplo la igualdad ante la ley, solamente de los españoles.

G.B.-Sí, eso es. Entonces, apliqué la distinción entre ética y moral, una distinción que veníamos desarrollando hace tiempo, y que también está 
fundada en esta perspectiva lógica. Dejando al margen las interpretaciones de la ética como discurso sobre la moral, que nos parecía una interpretación de origen germánico reciente; pero que en España impulsó Aranguren y, luego, la aceptó Muguerza, etc., siendo el criterio más seguido. A mí me parece sumamente peligroso esta distinción porque, si la ética es el discurso sobre la moral, para tener opiniones éticas había que ser profesor de ética o de filosofía. Entonces, se convertía la ética en una especie de discurso sobre la moral y se perdía la etimología de las dos palabras: donde «moral» son costumbres (mores) del grupo social, mientras que «ética» tiene que ver con la etología, con «ethos», etc., y se refiere más bien al individuo. Ahora, como el individuo es una abstracción, porque el individuo se supone siempre que forma parte de una totalidad atributiva, entonces resultaba que las normas éticas y la fuerza de obligar de las normas éticas tendrían distinta fuente de la fuerza de obligar de las normas morales; es decir, que si uno toma como referencia a la familia romana o a la nuestra, o la italiana (en Sicilia, donde está en vigencia la «vendetta»), esas grandes familias tienen unas normas morales y, luego, unas normas éticas: ¿de dónde vienen o cómo funcionan esas normas éticas? Las normas éticas tendrían, en principio, una especie de fundamento en el individuo en cuanto invariante de los diferentes grupos morales. Esto lo vi muy bien, hace algunos años, leyendo la Odisea: cuando viene alguien de una familia a una isla de aquéllas y lo recogen, lo consideran como el hijo de una familia, se conoce a su madre, etc. Hay una serie de conexiones. Sin embargo, cuando un individuo que pertenecía a un grupo pasa a otro grupo se establece una abstracción, inmediatamente, por la que el individuo comienza a ser enjuiciado como tal. Esto es lo que pasa en las guerras tantas veces: cuando, por ejemplo, los alemanes y los franceses que han cogido prisionero a otro, prevalece el hecho de que es un individuo porque a lo mejor es hijo mío, o hijo de esta señora... Quiero subrayar la idea de que el individuo como tal es una pura abstracción porque el individuo se forma en el grupo social. Esto no empece a que el individuo resulte abstraído como un invariante que tiene una entidad propia.

M.A.-Sobre esto, precisamente, versa la crítica que el joven Marx hace de la declaración de derechos, y a propósito de la distinción entre derechos del hombre y del ciudadano. Él decía que los derechos del ciudadano eran los derechos de la persona moral, abstracta, y los derechos del hombre eran los del hombre egoísta, los del hombre burgués.

G.B.-Sí, porque Marx estaba, seguramente, aplicando esto mismo a un caso concreto. La perspectiva de la que yo partía era...

M.A.-El concepto de hombre como ser genérico.

G.B.-Sí, eso es. Sinceramente, la distinción tiene un origen, en este caso, puramente lógico. Era simplemente la distinción entre clases distributivas 
y atributivas. Es una estructura puramente lógica que, para sorpresa mía, me parecía que funcionaba mucho más de lo que pudiera pensarse. Tomando los artículos de los derechos humanos, resulta que prácticamente todos los artículos son normas éticas. Has empezado por citar el sexo, la religión, la lengua... pues, todo lo que es la ciudad. Lo que queda realmente es ese individuo: el hombre sin atributos diríamos, porque ni es francés ni nada, pero que tiene un organismo y virtualmente puede ser cualquier cosa pero que no es ninguna. Ahora esto, a medida que aumenta el tráfico entre los pueblos, es una realidad.

M.A.-Pasemos ahora de los derechos humanos al Derecho. De una manera muy breve, ¿qué idea tiene usted del Derecho?

G.B.-En función de esto mismo que acabo de decir de la ética y la moral; me parece que en este sistema de ética y moral, suponiendo que la ética y la moral aparecen ya en sociedades primitivas, anteriores por ejemplo a la escritura, donde hay leyes no escritas: las leyes no escritas de Antígona, por ejemplo; que son normas morales, son normas de la familia, de la tribu. En estos casos hay unas normas éticas, porque la ética va apareciendo también históricamente, en el contexto de la familia. El fundamento de las normas éticas es el cuerpo, por eso aparecen en la familia, que es una organización que tiene sobre todo en cuenta el cuerpo del otro: el nacimiento, el entierro, la enfermedad, la alimentación... son las relaciones familiares, las llamadas relaciones íntimas, son los cuerpos. Pero el cuerpo es lo más universal que hay, es lo que todo el mundo tiene, el cuerpo desnudo. Aquello del «Cándido» de Voltaire, cuando va Cándido a Holanda y pide limosna en una puerta, aparece la señora de un pastor calvinista y le pregunta «¿qué quieres?» Y le contesta «quiero pan». Ella continúa: «pero, ¿tú crees que el Papa es el Anticristo?». A lo que Cándido contesta «a mí qué me importa que sea el Anticristo, yo lo único que sé es que tengo hambre». Entonces la señora le tira el Cristo a la cabeza y demás. Ahí el hombre está diciendo «tengo hambre»; es la relación ética fundamental y la norma ética es «ten pan» si eres calvinista como si quieres ser lo que sea. Este interés por el cuerpo, a mi juicio lo más universal, lo que es común a todos, este tipo de relaciones casi orgánicas, casi de primates, donde se explicitan es en la familia sobre todo, o en el prójimo. Cuando el individuo, aunque sea un individuo orgánico, es lejano, se le tiende a ver como de otra raza y de otra especie. Sencillamente. las relaciones éticas no funcionan. Empiezan a funcionar cuando el tráfico de unos y otros se hace mayor. Las relaciones éticas según esto se van desarrollando históricamente, a medida que lo hacen las sociedades. Entonces, si las normas éticas están funcionando dentro de relaciones que prevalecen en los grupos (las costumbres), resulta que los conflictos entre la ética y la moral son constantes y, por supuesto, los conflictos entre grupos morales; 
porque esos grupos son muy diferentes y, sobre todo, cuando se constituyen grupos políticos, cuando se pasa del nivel de tribu a un nivel de sociedad política, es porque hay una especie de confluencia de diferentes grupos prepolíticos. La confluencia hace que los conflictos se agraven y ahí vendrían las normas jurídicas, que tienen mucho que ver con lo que precede a la nación. Las normas jurídicas serían en este contexto normas destinadas a coordinar, organizar, resolver los conflictos entre ética y moral y morales entre sí, y, por eso, son tan heterogéneas, sus límites de aplicación estarían en función de hasta dónde llega el poder de quien las impone, que son las clases dominantes de esa organización. Las normas jurídicas eran fundamentales para poder funcionar a partir de un cierto nivel.

M.A.-La última cuestión. A Ud. que lee con cierta frecuencia escritos de filosofía del Derecho, me gustaría preguntarle: ¿Qué ve en ellos, qué le parece interesante con respecto a otros campos filosóficos? ¿Qué echa en falta? ¿Qué sugeriría a los filósofos del Derecho?

G.B.-Lo que veo es, primero, un conocimiento material, en el sentido de la materia misma del asunto; que no están hablando de abstracciones sino que ves ahí una serie de tratamientos de problemas reales, sacados de la realidad jurídica y moral; y, por tanto, es casi como una exigencia pedida internamente por las propias normas. Sinceramente, yo me veo en el pellejo de los filósofos del Derecho y envidiándolos porque yo haría cosas parecidas. Es lo que hay que hacer. Los problemas jurídicos, por lo menos tal como los veo, están tan llenos de problemas enrevesados, tan difíciles de establecer, por ejemplo: las relaciones entre unos grupos y otros; la prevalencia, la jerarquía de unas normas sobre otras; los episodios que tienen que ocurrir para que una ley se promulgue o no; la fuerza de obligar ¿de dónde procede? Es tal la maraña de cuestiones que, viendo a los filósofos del Derecho al tanto de esta maraña, encuentro, lo que para mí no es un defecto en absoluto, una gran escolástica, que me recuerda enteramente a la Escolástica. Yo me he tragado las cosas de Suárez, «De Legibus», por gusto; y lo de Domingo de Soto, «De Iustitita et Iure»; todos los clásicos del s. XVI. Es más, la argumentación de estos escolásticos -Suárez sobre todo, Domingo de Soto y Vitoria- que los leí en Salamanca, yo encontraba que era, así como decían que Euclides era la silogística de Aristóteles funcionando, pues esto era la argumentación filosófica funcionando. Era una argumentación dialéctica, donde había opiniones en contra y donde había que necesariamente fijar posiciones; y había que introducir una serie de terminología de distinciones que si no estás muy impregnado del asunto parecen escolásticas y «ad hoc», pero que son necesarias, porque si no, no puedes moverte. Son distinciones que se van sobreañadiendo y que, al que no ha hecho un análisis detallado y debido, pueden parecer que son superfluas, a primera 
vista; porque parecen que son muy sencillas pero cuando empiezas a ver la complejidad ves que son necesarias. El peligro puede ser que esa capa de distinciones necesarias aumente, de tal manera que interponga una pantalla entre el que está en esta especialidad y el que está fuera; es lo que pasa en toda escolástica. Ahora, particularmente, me gusta mucho. Quizá porque estoy un poco entrenado en estas disquisiciones escolásticas, lo encuentro muy familiar aunque la terminología sea diferente. Cuando lees a Bobbio y toda esta gente, encuentro algo muy familiar, es como si fueran de la misma raza. Yo veo a los filósofos del Derecho -la impresión más rápida que yo podría decir-, como continuadores de Domingo de Soto, de Vitoria, cambiando las referencias.

M.A.-Muchas gracias. 
DOXA 20 (1997) 